\title{
Mentoring as the basis for social business
}

\author{
Tatiana Artcer $^{1 \mathrm{a}}$, Anastasia Kharkovskaya ${ }^{1}$ \\ ${ }^{1}$ National Research Tomsk Polytechnic University, Lenin Avenue, 30, Tomsk 634050, Russia
}

\begin{abstract}
In this article the concept of mentoring as a basis for social business is considered. Besides, the ways of increase of efficiency of labor use through the institute of mentoring of young workers are considered by elderly people. Features of employment, work and dismissal of aging employees are also considered. Possibilities of application of mentoring, attraction of experience of pensioners taking into account the high level of their qualification are reflected. Tasks which the institute of mentoring will help to solve are formulated. The article examines the possibility of using mentoring and engaging retired employees with their experience, a high level of their education and professional qualification in the training of young inexperienced workers. Mentoring is presented as an element of social entrepreneurship.
\end{abstract}

\section{Introduction}

In modern conditions the developed countries face opposite tendencies: the reduced quantity of youth and the extending share of elderly persons. Within the next decades almost all countries will follow the same scheme of aging of the population [1].

Many employers consider that if the subordinate has reached a retirement age, then she/he needs to be dismissed. This tendency results in deficiency of labor in some branches of economy. However the achievement of a retirement age by the employee is not taken into consideration at all that she/he cannot continue work at the enterprise or in the organization. Thus, the relevance of this subject is defined.

The purpose is to consider the concept of mentoring as a basis for social business, as well as the ways of increasing of efficiency in the use of the labor through the institute of mentoring of young workers by elderly people and the features of employment, work and dismissal of aging employees.

The tasks are:

- to define the concept of social business;

- to consider the possibilities of mentoring young employees by elderly people;

- to analyse possibilities of application of mentoring, attraction of experience of pensioners taking into account the high level of their education and professional qualification;

- to consider features of employment, work and dismissal of aging employees.

\section{Results and discussion}

From the point of view of the world history, social business is a very young phenomenon. Over the ocean it exists for about 30 years, in Russia it is less than a decade. Despite so early age, social business takes place in the same row with noncommercial initiatives, charity, venture philanthropy and corporate social responsibility already today.

Social business is an innovative activity originally aimed at solving or mitigation of social problems on the terms of self-sufficiency and sustainability. Social business is a balance of the social purposes and a commercial component where money is not a purpose, but the means of achievement of these social purposes allowing a businessperson to remain steady and not be dependent on continuous donor injections [2].

The term «social business» refers to the activities combining the features of social work and business. On the one hand, the primary purpose of such an activity is the production of public goods, the solution of a certain social purpose; on the other hand, it has the characteristics of business - projects, i.e. it has to be commercially successful and profitable. Unlike any other business, social business does not have profit as the main objective but it is targeted at ensuring the sustainability of the social component, little dependence on sponsors and funders.

So social business can solve such social problem as deficiency of labor by means of introduction of mentoring elderly people at the enterprises. The possibility of participation of elderly persons as a part of labor will also be able to lower costs of training, professional development of young workers, to increase a share of intellectual property in assets of a firm, to improve competitiveness of the enterprise in the market.

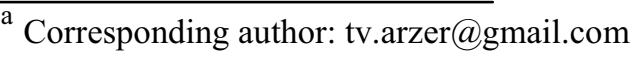






Fig. 1. The constituents of the social business

Mentoring is an effective and popular way of transfer of professional knowledge and abilities from a more skilled businessperson or the expert (mentor) to less skilled (protégé) [3]. Mentoring solves the following problems [1]:

- Improvement of the quality of preparation and qualification of the personnel.

- Development of the positive relation to work in new employees, an opportunity to quick attainment of the working indicators necessary for the company.

- Saving of time of unit managers for training and assessment of new workers.

- Providing mentors with experience of management and a possibility of career development, encouragement for good work, recognition of their merits before the company.

- Strengthening of command spirit, increasing of loyalty of the staff of the company to its system of values.

- Decreasing fluidity of personnel, reduction of the number of the employees who have left in time and right after a trial period.

The characteristic features of mentoring are presented in Figure 2.

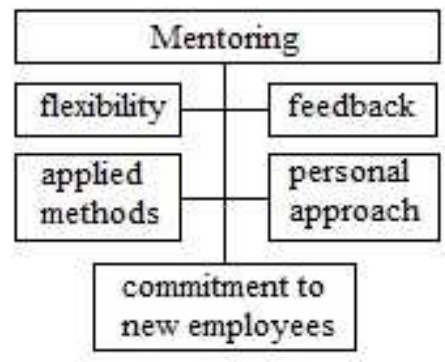

Fig. 2. Characteristic features of mentoring

These characteristics indicate:

- flexibility (mentoring can be carried out in a variety of ways and methods);

- applied methods (mentoring is focused on the professional activity of employees, and can cover the whole range of these activities);

- personal approach (mentoring is focused directly on the needs and interests of a new employee);

- commitment to new employees (the mentoring system considers the potential of young specialists);

- feedback (mentoring is well combined with other methods of experience transfer).
On the basis of the significant advantages of mentoring it can be concluded that this method is the most effective in the formation of experience and competence for the professionals who have just joined the company.

Efficiency of mentoring is explained by its individual character, no other form of education can be addressed in such way and brought closer to real conditions. The mentor can quickly react to the mistakes made by its protégé, sort them out in details and point to the correct course of work.

Many domestic enterprises, created during the Soviet period and belonging to the defense industry complex, are in great need in effective ways of a solution of the problem of preservation of unique knowledge today. In the companies there are a lot of young unexperienced employees and many "veterans" who will shortly go on well-deserved retirement. Often leaving the enterprises, such honored workers carry away unique knowledge and experience with themselves, which cannot be reproduced in short terms even in case of considerable financial and other types of expenses for training of young specialists. In this situation employees and heads loyal to the enterprise express concern about destiny of the organization after departure of "veterans".

In line with this there is a need to explore the category of «older workers», its employment pattern and finding the best practice of the experience and knowledge transfer from the more qualified mature specialists to the younger workers of an enterprise.

In modern conditions, the transfer of expertise to new employees is the primary method of training within the firm, since no external training can prepare a novice for the professional activities in a particular company.

For many pensioners it is very important "to be socially significant people. The people, who have retired having higher education degrees, being doctors of science, or experts with work experience of more than 25-30 years, are a universal fund of professionals that can work to increase the efficiency of a work force of the enterprise.

Mentoring acts as a mechanism for the transfer of specific and important knowledge, experience, skills, techniques and methods of work, as well as the establishment of the corporate culture of an enterprise. The elderly people who have worked for one and the same company for many years have all the qualities of a mentor.

People of old age have to be mentors in administrative professions where experience is a more important factor defining labor productivity. Indicators of work of elderly workers are, as a rule, not worse than indicators of their younger colleagues. Workers of advanced age often rely on knowledge and qualifications and skills, and also on the general professional experience which has been gathered during their labor life. In their work elderly workers introduce such qualities as accuracy, reliability and ability to communicate with clients and colleagues, stability, decrease in the number of voluntary truancies, turnover of staff, loyalty of the company. As practical experience and research testify, the workers of advanced age, 
engaged in the positions corresponding to their individual qualifications, show high efficiency of work [1].

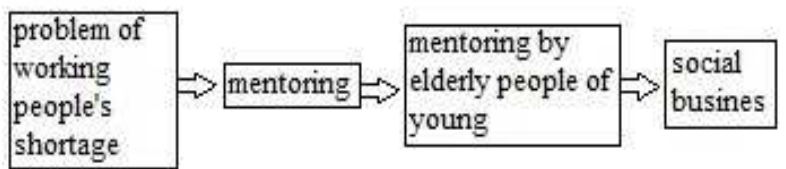

Fig. 3. The way to increase the efficiency of labor through the institute of mentoring of young workers by elderly people

If a system of mentoring is built correctly, all the important skills and experiences will remain within the company, and will be transferred «from generation to generation, to new employees. It will make the newcomers' integration into the team easier, as well as it can help HR-managers to reduce the staff training costs.

According to Article 3 of the Labor code of the Russian Federation everyone has equal opportunities for realization of the right to work. Nobody can be limited in the labor law and freedoms [4].

Let us consider employment, work and dismissal of pensioners.

1. Employment of aging pensioners does not differ from the usual procedure of employment of new employees, as existence of the similar status in itself cannot be the reason for any restrictions in the sphere of work.

Thus, the age limit after which the execution of an employment agreement is forbidden is not established. Refusal in employment of a pensioner can be reasoned only by the lack of necessary business qualities. As unreasonable refusal in employment is forbidden, the employer, upon the demand of the candidate, is obliged to reason the refusal stated in writing (Article 64 of the Labor Code of the Russian Federation). It is also necessary to remember that age restrictions in employment can be established not only by the Labor Code of the Russian Federation, but also by special Federal laws [5].

2. The labor legislation has not provided a special ban on establishment of a trial period at employment of pensioners. The similar condition can be included in the labor agreement and the order in accordance with general practice. The employer should remember that the test can be established only in the presence of mutual consent of the parties. If in the labor contract there is no condition about the test, it is considered that the worker is employed in accordance with general practice [5].

3. As in combination the legislation does not contain a direct ban on work of pensioners, the persons belonging to this category having the right to conclude labor contracts for performance of other duties in the period when they are free from the main work, at the same or other employer's work

3. In the first case it is internal combination of jobs, in the second case the external one will take place. At the same time all guarantees and compensations, which are applied to the ordinary employees, (the annual paid vacation, payment of the sick-list, compensation for unused holiday at dismissal) are retained for the pensioner working part-time [5].

4. In case of an execution of an employment agreement with the pensioner, there is a lawful opportunity by agreement of the parties to bring a condition about an urgent character of the contract. The specified opportunity is the main feature in this case. The employer should remember that inclusion of a condition about the urgent character of the labor agreement is forcibly inadmissible. It is not necessary to insist on a similar condition and on the existing possibility of registration of the termless contract. Otherwise, if in the course of judicial proceedings it is confirmed that coercion took place, such contract will be recognized by the prisoner for uncertain term. One more nuance in this case is that it is possible to bring a condition about urgency only during registration for work of the repeatedly accepted pensioner. An employer is not allowed to replace the contract concluded for an indefinite term with the urgent contract only because a worker achieves a retired age and is granted a pension [5].

5. In the conditions of crisis, one of the ways to decrease the expenses of the enterprise is reduction of the personnel. Such method is quite reasonable and lawful. However, in practice staff pensioners are dismissed in the first place, which leads to a reduction. Similar actions of the employer are possible to define, having studied the regulatory base of the regulating matter.

According to clause 1 of Article 77 of the Labor Code of the Russian Federation, among the reasons for cancellation of the employment contract due to achievement of a certain age by the worker is not designated. However, clause 2 of Art. 77 of the Labor Code of the Russian Federation allows the possibility of the termination of the employment contract on other bases, provided by the legislation. For example, the age qualification is determined in the Federal law of July 27, 2004 No. 79-FZ concerning the age of civil servants. Thus, the order of dismissal of pensioners at reduction does not differ from the general order established for persons of other age category.

As reduction of the pensioner from work has to be carried out in the general order, such workers no more than in two months are warned about the forthcoming termination of the labor relations. The similar prevention has to be carried out personally on receipt.

The duty of the employer is to offer such employee the vacancies which are available at the enterprise. At the same time, it is worth remembering that in case of release of positions after the notification of the employee of reduction, they also have to be offered as an option of employment [5].

6. At many enterprises, pensioners instead of dismissal are just transferred to other department to a less responsible position. But it is possible only under certain conditions:

- transfer of the worker to other department or to other position has to be done only with her/his permission; 
- if the subordinate agrees to such outcome, then the official transfer of the employee to the new constant place of work has to be issued;

- the option of the worker's dismissal from the previous position and her/his subsequent employment in other works is possible with the conclusion of the new contract.

To transfer the colleague to the new place of work, it is necessary:

- to sign the employment contract in which new functions and important conditions of implementation of working activity will be specified;

- to issue the order on the transfer;

- to display the information on transfer to the new place of work in the service record of the worker;

- on the third page of the personal card of the worker it is necessary to put a signature about the transition and return it to her/him.

It is possible to quit the job on the reason of retirement without warning the employer in two weeks only once.

If in connection with retirement the colleague leaves the enterprise, she/he has to have the note why she/he left the place of work [6].

Table 1. Features of employment, work and dismissal of employees on age.

\begin{tabular}{|c|c|}
\hline $\begin{array}{c}\text { Employm } \\
\text { ent on age }\end{array}$ & $\begin{array}{c}\text { does not differ from the usual procedure } \\
\text { of employment of new employees }\end{array}$ \\
\hline $\begin{array}{c}\text { Trial } \\
\text { period }\end{array}$ & $\begin{array}{l}\text { a special ban on establishment of a trial } \\
\text { period at employment of pensioners is not } \\
\text { provided }\end{array}$ \\
\hline $\begin{array}{c}\text { Combinin } \\
\text { g jobs }\end{array}$ & $\begin{array}{l}\text { in combination the legislation does not } \\
\text { contain a direct ban on work of pensioners }\end{array}$ \\
\hline $\begin{array}{c}\text { Urgent } \\
\text { employment } \\
\text { contract }\end{array}$ & $\begin{array}{l}\text { there is a lawful opportunity by } \\
\text { agreement of the parties to bring in a } \\
\text { condition about the urgent character of the } \\
\text { contract }\end{array}$ \\
\hline $\begin{array}{c}\text { Reduction } \\
\text { of pensioners }\end{array}$ & $\begin{array}{l}\text { among the reasons for cancellation of the } \\
\text { employment contract the achievement of a } \\
\text { certain age by the worker is not designated }\end{array}$ \\
\hline $\begin{array}{c}\text { Dismissal quit the job on the reason of } \\
\text { of pensioners }\end{array}$ & $\begin{array}{l}\text { retirement, without warning the employer in } \\
\text { two weeks, is possible only once }\end{array}$ \\
\hline
\end{tabular}

From all previously mentioned, it is possible to draw a conclusion that work of people of a retirement age does not differ from work of young experts. Also people of a retirement age can be more preferable to the employer as they are valuable employees with a wide experience of work.

\section{Conclusion}

In the conclusion it should be noted the following:

1. Social business is a business solution of a social problem. The social problem, which the social businessman tries to solve, is a starting point of her/his business. There is no problem if there is no social businessperson. Social business can solve a problem of shortage of workforce by means of introduction of elderly people's mentoring of young experts.

2. Every year the need for skilled workforce grows, and it became obvious that the senior generation can make the positive contribution to production development. Thus, it is necessary to introduce the system of mentoring, to use the expert potential of skilled workers more widely.

3. People of old age have to be mentors in administrative professions where experience is a important factor defining labor productivity. Indicators of work of elderly workers are, as a rule, not worse than indicators of their younger colleagues. Workers of advanced age often rely on knowledge and qualifications and skills, and also on the general professional experience which has been accumulated during their labor life.

4. The mentoring system is a necessary element of a corporate culture of a company. For this process to continue in a proper way, it is necessary to keep company executives' interested in this issue. If the introduction of mentoring is not put under control, the process will not give the desired effect.

5. A proper mentoring system construction results in preserving all the important knowledge and skills within the organization (experienced employees of the company will share them with a new generation of specialists). Furthermore, such cooperation in a company strengthens team spirit and corporate culture. As a consequence, a company acquires a highly professional and motivated team of employees that share its values and culture.

6 . The quality of the work performed by people of a retirement age does not differ from that of young specialists. Also people of a retirement age can be more preferable to the employer as they are valuable employees with a wide experience of work.

\section{References}

1. T. Artser, M. S. R. and I. (2015)

2. Social business [An electronic resource. URL: http://www.nb-forum.ru/social/ (2016)

3. S. Sponem, C. Lambert, M. A. R, 51, (2016)

4. D. Clutterbuck, B. Rose, T. to T. \& F., 21 (2002)

5. T. Artcer, X. Galiegue, G. Mondello, P. - S. and B. S., 53-57 (2015)

6. Z. Fund, Teachers \& Teaching, 16(6), (2010)

7. P. Gronn, Distributed leadership as a unit of analysis. Leadersh. Quart., 13(4), (2002) 